University of New Hampshire

University of New Hampshire Scholars' Repository

$1-19-2016$

\title{
Rhythms of locomotion and seasonal changes in activity expressed by horseshoe crabs in their natural habitat
}

\author{
Winsor H. Watson III \\ University of New Hampshire, Durham, win.watson@unh.edu \\ Suzanne K. Johnson \\ University of New Hampshire, Durham \\ Colin D. Whitworth \\ University of New Hampshire, Durham \\ Christopher C. Chabot \\ Plymouth State University
}

Follow this and additional works at: https://scholars.unh.edu/jel

\section{Recommended Citation}

Watson, W. H. III, S. K. Johnson, C. D. Whitworth and C. C. Chabot. 2016. Rhythms of locomotion and seasonal changes in activity expressed by horseshoe crabs in their natural habitat. Mar. Ecol. Prog. Ser. 542: 109-121. https://doi.org/10.3354/meps11556

This Article is brought to you for free and open access by the Institute for the Study of Earth, Oceans, and Space (EOS) at University of New Hampshire Scholars' Repository. It has been accepted for inclusion in Jackson Estuarine Laboratory by an authorized administrator of University of New Hampshire Scholars' Repository. For more information, please contact Scholarly.Communication@unh.edu. 


\title{
Rhythms of locomotion and seasonal changes in activity expressed by horseshoe crabs in their natural habitat
}

\author{
Winsor H. Watson III ${ }^{1, *}$, Suzanne K. Johnson ${ }^{1}$, Colin D. Whitworth ${ }^{1}$, \\ Christopher C. Chabot $^{2}$
}

\author{
${ }^{1}$ Department of Biological Sciences, University of New Hampshire, Durham, NH 03824, USA \\ ${ }^{2}$ Department of Biological Sciences, MSC\#64, Plymouth State University, Plymouth, NH 03223, USA
}

\begin{abstract}
The American horseshoe crab Limulus polyphemus expresses both tidal and daily rhythms of locomotion in the laboratory and the tidal rhythms can be entrained to artificial tides. The main purpose of this study was to determine the types of rhythms horseshoe crabs express when freely moving in their natural habitat where they are exposed to natural light:dark and tidal cycles. A secondary goal was to determine if their overall activity patterns and depth preferences changed during the year. In 2010 and 2011, 20 adult horseshoe crabs (11 males, 9 females) were fitted with ultrasonic tags and released in the Great Bay Estuary, NH, USA. The tags transmitted acceleration and depth data every 3 to 5 min from June until December during the year in which they were tagged, and from March to May of the following year. Acoustic transmissions from the tags were detected and logged by a series of VR2W receivers moored throughout the estuary. Accelerometer data were used to assess when animals were active and to determine (1) whether they were expressing tidal or daily rhythms and (2) their overall activity level each month. We discovered that horseshoe crabs were just as likely to express tidal rhythms as daily rhythms, despite being continuously exposed to natural tide cycles. In addition, there was a tendency to move into deeper water and become less active as water temperatures cooled in the fall, and then to move up into the estuary and become more active as water temperatures warmed in the spring.
\end{abstract}

KEY WORDS: Telemetry · Accelerometers $\cdot$ Estuary $\cdot$ Horseshoe crab $\cdot$ Limulus $\cdot$ Tidal rhythms Daily rhythms

\section{INTRODUCTION}

Endogenous biological rhythms allow animals, plants, and bacteria to synchronize with and anticipate natural fluctuations of light and dark as well as tidal cycles (DeCoursey 2004). While $\sim 24 \mathrm{~h}$ daily rhythms are driven by endogenous circadian clocks and primarily entrained by photoperiod cues (Johnson et al. 2004), organisms can use a variety of other cues, such as changes in water depth and currents, to entrain their tidal rhythms (See Palmer 1995 for a review). Thus, while the endogenous $\sim 12.4 \mathrm{~h}$ circatidal rhythms of many organisms will persist but 'drift' when exposed to constant conditions in the laboratory, in nature they tend to be closely synchronized to natural cyclic tidal cycles.

The American horseshoe crab Limulus polyphemus is found along the Atlantic coast of the United States and the Gulf of Mexico. It is one of the oldest marine arthropods, with a fossil record dating back 445 million yr (Shuster 2001, Rudkin \& Young 2009). In late spring and early summer, horseshoe crabs move 
into shallow water and mate at the water/beach interface when the tides are high (Rudloe 1980, 1985, Cohen \& Brockmann 1983). Commencement of mating activity appears to be triggered by changes in temperature and photoperiod, as well as water level changes (Rudloe 1980, Cohen \& Brockmann 1983, Barlow et al. 1986, Ehlinger et al. 2003, Watson et al. 2008). During the mating season, horseshoe crab activity appears to be synchronized with the tides, as they are only consistently observed at the water's edge during high tides. A recent ultrasonic telemetry study confirmed that individuals tend to be most active during a particular portion of the tidal cycle during the mating season; however, the duration in which data were continuously obtained from a single animal was limited since they would often move out of the range of the buoys in the fixed VRAP array (Watson \& Chabot 2010). Some horseshoe crabs continue to be active at high tide after the mating season ends, likely due to their tendency to move into mudflats at high tide to dig pits and forage for food (Lee 2010). Therefore, in order to extend our understanding of horseshoe crab behavior and biological rhythms, we aimed to obtain activity data from individual crabs long enough to permit a more rigorous analysis of the dominant patterns of activity they express in their natural habitat throughout most of the year.

In the laboratory, horseshoe crabs express both tidal and daily rhythms; most of those that express a daily rhythm are diurnal (most active in the day), while fewer are nocturnal (most active at night) (Chabot et al. 2004). Most crabs express a tidal rhythm even when they are not exposed to tidal cues, indicating that this behavior is driven by an endogenous circatidal clock (Chabot et al. 2007). Moreover, these endogenous tidal rhythms can be entrained by changes in water depth that mimic the tidal cycle (Chabot et al. 2004, 2008, 2011, Watson et al. 2008, Chabot \& Watson 2010). Horseshoe crabs that were placed in running wheels anchored to the bottom of the Great Bay Estuary also expressed a tidal rhythm of activity that was synchronized to the tidal cycle (Watson et al. 2009). However, when they were suspended in similar running wheels underneath a floating dock so they did not experience the depth changes associated with the tides, they tended to be most active during the day (Watson et al. 2009). Therefore, the hypothesis this study was designed to test is that horseshoe crabs in their natural environment are more likely to express a tidal than a daily rhythm of activity, since they continually experience rhythmic changes in water depth, and thus cyclic fluctuations in water pressure.

As mentioned above, some horseshoe crabs also express daily patterns of activity when exposed to a light:dark (L:D) cycle in the laboratory. However, these daily patterns of activity do not appear to persist in constant darkness, suggesting that they do not possess a circadian clock that controls locomotion even though they do have a circadian clock that influences visual sensitivity (Barlow 1983). Rather, it appears that the activity of some animals might be suppressed by exogenous cues during the day or night, yielding the daily pattern observed in some animals exposed to artificial or natural L:D cycles (referred to as masking; Chabot et al. 2007). Thus, we also expected that some animals in their natural habitat (where they always experience natural L:D cycles) would tend to be more active during the day or night.

While a great deal is understood about the mating behavior of horseshoe crabs (because they repeatedly approach beaches during the spring and early summer high tides and are thus readily observed), much less is known about their movements and behaviors during the rest of the year. They tend to live in bays and estuaries where visibility is limited, and thus few people have observed them in their natural habitat. Several recent studies have taken advantage of various types of biotelemetry and digital video technologies to shed light on their large-scale movements (Schaller et al. 2010, Smith et al. 2010) and their tendency to forage in intertidal mudflats (Lee 2010), and these studies have provided some insight into their natural history. In general, in areas from the midAtlantic States northward, horseshoe crabs tend to be fairly sedentary during the colder months and then increase their activity as water temperatures warm in the spring (Moore \& Perrin 2007, JamesPirri 2010, Schaller et al. 2010). During this time period, they move towards spawning beaches, which are typically in warmer, shallower bays and estuaries (James-Pirri et al. 2005, Moore \& Perrin 2007, James-Pirri 2010, Schaller et al. 2010, Smith et al. 2010). Then, after spending much of the summer and early fall foraging for prey, they move into deeper water to overwinter (Moore \& Perrin 2007, James-Pirri 2010, Schaller et al. 2010). While our investigation was primarily focused on the activity rhythms expressed by freely moving horseshoe crabs, we also took advantage of the opportunity to address 2 additional questions. First, do horseshoe crabs have preferences for a certain depth strata, 
and does this change on a seasonal basis? Second, does their overall activity change as water temperatures decrease in the fall and increase in the spring?

The use of ultrasonic telemetry tools to study the physiology and behavior of aquatic species has increased over the past $10 \mathrm{yr}$, and as a result we are beginning to gain new insights into the behavior of these animals in their natural habitats. While telemetry has traditionally been used to simply track animal movements, there are now devices that also transmit data about the activity of the animals as well as the environmental conditions around them (Nielsen et al. 2009, Cooke et al. 2013). Accelerometer tags are particularly useful for studying animal behavior, and their use has increased considerably in recent years (Williams et al. 2004, Wilson et al. 2006, Whitney et al. 2007, Payne et al. 2011, Broell et al. 2013, Lyons et al. 2013). In this study, we employed ultrasonic tags that transmitted accelerometer and depth data. This allowed us to determine if a horseshoe crab was active or not, and to correlate its behavioral state with the depth of the water and the tidal cycle.

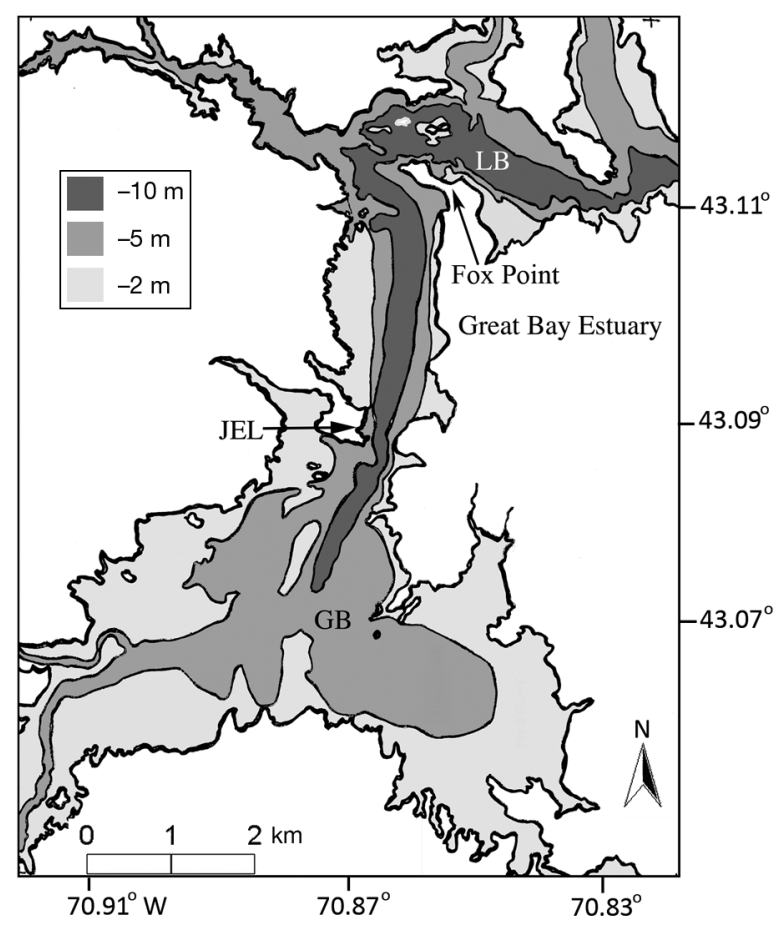

Fig. 1. Study location in Great Bay estuary, NH, USA. Most data were obtained from animals that were resident in the area between the middle of Great Bay (GB) and Little Bay (LB). A deep (>10 m depth) channel runs the length of the estuary and Piscataqua River, connecting LB and GB with the Gulf of Maine. JEL = Jackson Estuarine Laboratory

\section{MATERIALS AND METHODS}

\section{Study animals and location}

This study took place in the Little Bay and Great Bay portions of the Great Bay Estuary, New Hampshire (Fig. 1), where the average tidal range varies from 2.0 to $2.7 \mathrm{~m}$ and currents range from 0.5 to $2.0 \mathrm{~m}$ $\mathrm{s}^{-1}$ (Short 1992). Adult horseshoe crabs were collected from the Great Bay estuary either while they were spawning near the Jackson Estuarine Laboratory (JEL; Fig. 1), or by SCUBA divers during other times of the year. Over $3 \mathrm{yr}$, a total of 22 adult horseshoe crabs were equipped with VEMCO V9AP ultrasonic transmitters (Table 1). During May and June 2010, 9 horseshoe crabs (4 male, 5 female) were captured while spawning and fitted with transmitters. This was repeated in the spring of 2011, with 7 additional animals ( 6 male, 1 female) receiving transmitters. Finally, a group of 6 animals ( 2 male, 4 female) were captured by SCUBA divers near Fox Point in late fall 2011, equipped with transmitters, and immediately released at the same location. The first 2 sets of transmitters (activated in spring 2010 and 2011),

Table 1. Information about the 22 horseshoe crabs Limulus polyphemus fitted with ultrasonic transmitters in this study. The ID \#s for the V9AP ultrasonic transmitters listed in the first column have one number for depth and a sequential number for acceleration data

\begin{tabular}{|c|c|c|c|c|}
\hline ID\# & Sex & $\begin{array}{c}\text { Carapace } \\
\text { width }(\mathrm{cm})\end{array}$ & $\begin{array}{c}\text { Release } \\
\text { date } \\
\text { (mm/dd/yy) }\end{array}$ & $\begin{array}{c}\text { Days of } \\
\text { data }\end{array}$ \\
\hline $2730 / 2731$ & $\mathrm{~F}$ & 19.1 & $6 / 9 / 10$ & 63 \\
\hline $2732 / 2733$ & M & 16.5 & $6 / 9 / 10$ & 103 \\
\hline $2734 / 2735$ & $\mathrm{~F}$ & 17.3 & $6 / 18 / 10$ & 2 \\
\hline $2736 / 2737$ & $\mathrm{~F}$ & 22.1 & $6 / 18 / 10$ & 2 \\
\hline $2738 / 2739$ & $\mathrm{~F}$ & 16 & $6 / 18 / 10$ & 98 \\
\hline $2740 / 2741$ & $\mathrm{M}$ & 16 & 6/18/10 & 89 \\
\hline $2742 / 2743$ & $\mathrm{M}$ & 13.9 & $6 / 18 / 10$ & 67 \\
\hline $2744 / 2745$ & $\mathrm{M}$ & 14.2 & $6 / 18 / 10$ & 141 \\
\hline $2621 / 2622$ & $\mathrm{~F}$ & 19.1 & $8 / 19 / 10$ & 40 \\
\hline $5859 / 5860$ & $\mathrm{M}$ & 17.1 & $6 / 30 / 11$ & 44 \\
\hline $5861 / 5862$ & $\mathrm{M}$ & 15.7 & $6 / 30 / 11$ & 28 \\
\hline $5863 / 5864$ & $\mathrm{~F}$ & 20.3 & $6 / 30 / 11$ & 69 \\
\hline $5865 / 5866$ & $\mathrm{M}$ & 15.2 & $6 / 15 / 11$ & 154 \\
\hline $5867 / 5868$ & M & 14.2 & $6 / 30 / 11$ & 71 \\
\hline $5869 / 5870$ & $\mathrm{M}$ & 16.5 & $6 / 30 / 11$ & 37 \\
\hline $5871 / 5872$ & $\mathrm{M}$ & 13.9 & $6 / 30 / 11$ & 73 \\
\hline $6502 / 6503$ & $\mathrm{~F}$ & 17 & $11 / 8 / 11$ & 23 \\
\hline $6504 / 6505$ & $\mathrm{~F}$ & 20 & 11/8/11 & 29 \\
\hline $6506 / 6507$ & $\mathrm{M}$ & 14 & 11/8/11 & 23 \\
\hline $6508 / 6509$ & $\mathrm{M}$ & 13.9 & $12 / 5 / 11$ & 29 \\
\hline $6748 / 6749$ & $\mathrm{~F}$ & 17 & $12 / 5 / 11$ & 18 \\
\hline $6750 / 6751$ & F & 17 & 12/5/11 & 31 \\
\hline
\end{tabular}


were programmed to record data all summer and fall, shut off for the winter to conserve power, and reactivate the following spring. The final group (tagged in fall 2011), was programmed to transmit data in the fall, and then re-activate in March and transmit data during spring 2012. For 2 animals, useful data were only obtained for $2 \mathrm{~d}$ and thus their data were not included in the final analyses.

Transmitters were either inserted into the anterior-dorsal region of the carapace or attached to the dorsal carapace (Schaller et al. 2010, Watson \& Chabot 2010). For internal placements, an incision was made in the carapace with a utility knife and the transmitter was inserted through it into the frontal region of the carapace. The insertion site was then covered with duct tape held in place with superglue. External transmitters were first glued inside a piece of Tygon tubing containing holes so that cable ties could be passed through them. Two holes were drilled in the posterior margin of the prosoma and the cable ties were slipped through the holes and closed. Duct tape was then glued over the transmitters to make a smooth surface that would not get snagged on debris underwater.

\section{Acoustic transmitters and receivers}

In order to determine the range of the transmitters (pingers), and whether transmissions diminished when animals were buried in the sediment, we conducted a preliminary transmission range study in October 2011, followed by a more rigorous study in July 2012. In 2011, we buried 3 V9AP transmitters at 3 different depths in the sediment $(0,7,14 \mathrm{~cm})$ in $\sim 2 \mathrm{~m}$ of water, and monitored their transmissions using 2 VR2W receivers (VEMCO) located 50 and $150 \mathrm{~m}$ away. Transmissions were monitored for $4 \mathrm{~d}$, so that we could also determine if the tides had any impact on the number of transmissions detected. In 2012, SCUBA divers placed a V9 tag on a lobster trap located on the bottom, in $\sim 5 \mathrm{~m}$ of water, and a series of 4 VR2W receivers were moored approximately 10 , 100,200 , and $300 \mathrm{~m}$ away from the pinger. Data were collected for $\sim 24 \mathrm{~h}$; on Day 2 , divers buried the pinger $3 \mathrm{~cm}$ into the sediment and data were collected for an additional $24 \mathrm{~h}$. This process was repeated on Day 3, with the pinger submerged $6 \mathrm{~cm}$ into the sediment. Data from both range tests were analyzed to determine if distance, tides, and transmitter depth had any impact on the number of times a receiver detected a pinger.
Throughout most of the study, acoustic transmissions were received and logged by 7 VR2W receivers moored about $500 \mathrm{~m}$ apart throughout Little Bay and Great Bay (Fig. 1). Most of the tagged horseshoe crabs spent the majority of their time in the upper portion of Little Bay, so the 7 VR2W receivers were moored between Fox Pt. and JEL (Fig. 1). This area of Little Bay is about $3 \mathrm{~km}$ long and $1 \mathrm{~km}$ wide. The horseshoe crabs were almost always located along the eastern shore, therefore the 7 VR2Ws were moored $\sim 0.5 \mathrm{~km}$ apart at a depth of $\sim 7 \mathrm{~m}$ along the eastern edge of the channel in Little Bay. With this arrangement, there was a high probability that at any given time 1 or 2 receivers would detect signals from a specific transmitter. Receivers were downloaded weekly and if one of the horseshoe crabs was not detected by any of the receivers it was located manually using a VR100 receiver and omnidirectional hydrophone slowly towed behind a small boat. If a receiver was not detecting any animals or was collecting redundant data, it was moved so that it could receive data from this animal. This approach also allowed us to track horseshoe crab movements throughout the study. The total number of days that data were received for each crab ranged from 2 to 154 d (Table 1). Throughout the study, water temperature was continuously recorded using a YSI water quality sonde located at $5 \mathrm{~m}$ depth, just off the JEL dock.

\section{Data analyses}

The data obtained from the accelerometer transmitters were used to determine when animals were active or not. The V9AP accelerometer transmitter calculates a value that represents the root mean square acceleration based on the contribution of accelerations from each of the 3 axes $(x, y, z)$, averaged over a set interval (20 s):

$$
\mathrm{m} \mathrm{s}^{-2}=\sqrt{\left(x^{2}+y^{2}+z^{2}\right.}
$$

Based on the specifications programmed into the tags used in this study, accelerometer data only recorded $10 \%$ of every 3 to 5 min data collection interval. Furthermore, even if animals were only moving a small amount the transmitters would provide a value; therefore, we needed to determine a threshold output that represented actual locomotion. This was achieved by collecting digital videos of horseshoe crabs while they moved around (or remained stationary) in $2 \mathrm{~m}$ diameter tanks, while we simultaneously recorded the output of implanted 
V9AP tags with VR2W receivers. Periods of activity and inactivity were determined from the videos, and the accelerometer tag output values were matched with these periods to determine a threshold value that represented true locomotion. This threshold value $\left(0.1 \mathrm{~m} \mathrm{~s}^{-2}\right)$ was then used to filter data collected in the field and to determine if, during each transmission, an animal was active or inactive. These data were then lumped into $10 \mathrm{~min}$ bins, and if an animal was active during any of the sampling times in that 10 min block it was considered to have been active for that whole block of time. This approach was used for 3 reasons. First, as stated above, the accelerometer tags do not average data for the entire 3 to $5 \mathrm{~min}$ and then transmit the averaged data. Rather, they simply transmit data that has been averaged over the $20 \mathrm{~s}$ prior to each transmission. Thus, it is possible that a period of activity could be missed if the animal was active for most of the inter-transmission interval, but then inactive for that $20 \mathrm{~s}$ period prior to the transmission. Second, based on laboratory and field observations, when horseshoe crabs are active they tend to be active for long periods of time rather than intermittently. Therefore, if they are active during one of several transmissions received during a $10 \mathrm{~min}$ block, it is likely they were active during most of that 10 min period. Finally, we wanted to combine our data into discrete blocks of time, but the data were transmitted at random intervals. This necessitated lumping the data into bins; 10 min bins were chosen because that length of time was long enough to allow for the detection of more than one transmission, and yet short enough to yield accurate periodograms.

These data were then used to calculate the total amount of time an animal was active during each hour and each day. However, it should be noted that pingers were often not detected for several hours, possibly because (1) animals were out of range, (2) they were buried in the sediment, (3) signals were attenuated by currents and thermoclines (Mathies et al. 2014), or (4) some combination of these factors. Based on our calibration tests, when animals were in range (based on receiving a large number of detections during certain times of the day), the most likely cause of missed transmissions was attenuation of signals due to animals being buried in the sediment. Therefore, calculations of the percent of the time/day that a horseshoe crab was active were made by dividing the amount of time when accelerometer pings were received that were above the threshold value that indicated animals were active (i.e. $>0.1 \mathrm{~m} \mathrm{~s}^{-2}$ ), by $24 \mathrm{~h}$.
These values were also used to determine the type of biological rhythm a given animal expressed, using the program Clocklab (Actimetrics). Clocklab was used both to plot actograms and determine the period ( $t a u)$ of the dominant, statistically significant, rhythm in the 10.4 to $14.4 \mathrm{~h}$ (circatidal) or 22 to $26 \mathrm{~h}$ (circadian) range exhibited by each animal. Finally, for those animals that expressed a daily rhythm of activity, the percent of each day and night during which they were active was averaged for as many days as clear data were available and a paired Student's $t$-test was used to determine if there was a significant difference between the amount of time they were active in the day versus the night. Results were considered significant at $\mathrm{p}<0.05$.

\section{RESULTS}

\section{Pinger calibrations}

Based on previous studies, our hypothesis was that when animals were buried, transmitter output would be attenuated. In order to test this hypothesis, we compared our ability to detect pingers that were buried at different depths, using VR2W receivers stationed at different distances away from the transmitters. In the 2011 trial we used 3 transmitters buried at different depths, and it was clear that being buried attenuated the signals (Fig. 2A). In comparison to the pinger on the surface, $40 \%$ fewer transmissions were detected by the receiver that was $50 \mathrm{~m}$ away from the pinger buried $7 \mathrm{~cm}$ deep and $63 \%$ fewer pings from the transmitter buried $14 \mathrm{~cm}$ deep. The receiver that was $150 \mathrm{~m}$ away did not detect any signals from the pinger buried the deepest. In addition, there was no clear evidence during this trial that the tides or time of day influenced the percentage of transmissions that were detected (Fig. 2A).

In the 2012 study, receivers were located 10, 100, 200 , and $300 \mathrm{~m}$ away from a single pinger. When the pinger was on the surface, the 2 closest receivers detected 142 and 135 pings $\mathrm{h}^{-1}$, respectively. However, the receiver that was $200 \mathrm{~m}$ away picked up only $34 \%$ of the pings detected by the closest receiver, and the one that was $300 \mathrm{~m}$ away detected only $9 \%$. Thus in this habitat, it was difficult for receivers $>200 \mathrm{~m}$ away to detect animals that were not buried. When pingers were buried $3 \mathrm{~cm}$ into the sediment (which is somewhat shallow for a horseshoe crab in the Great Bay estuary based on diver observations), transmissions were reduced the most at the receiver that was $200 \mathrm{~m}$ away (from 

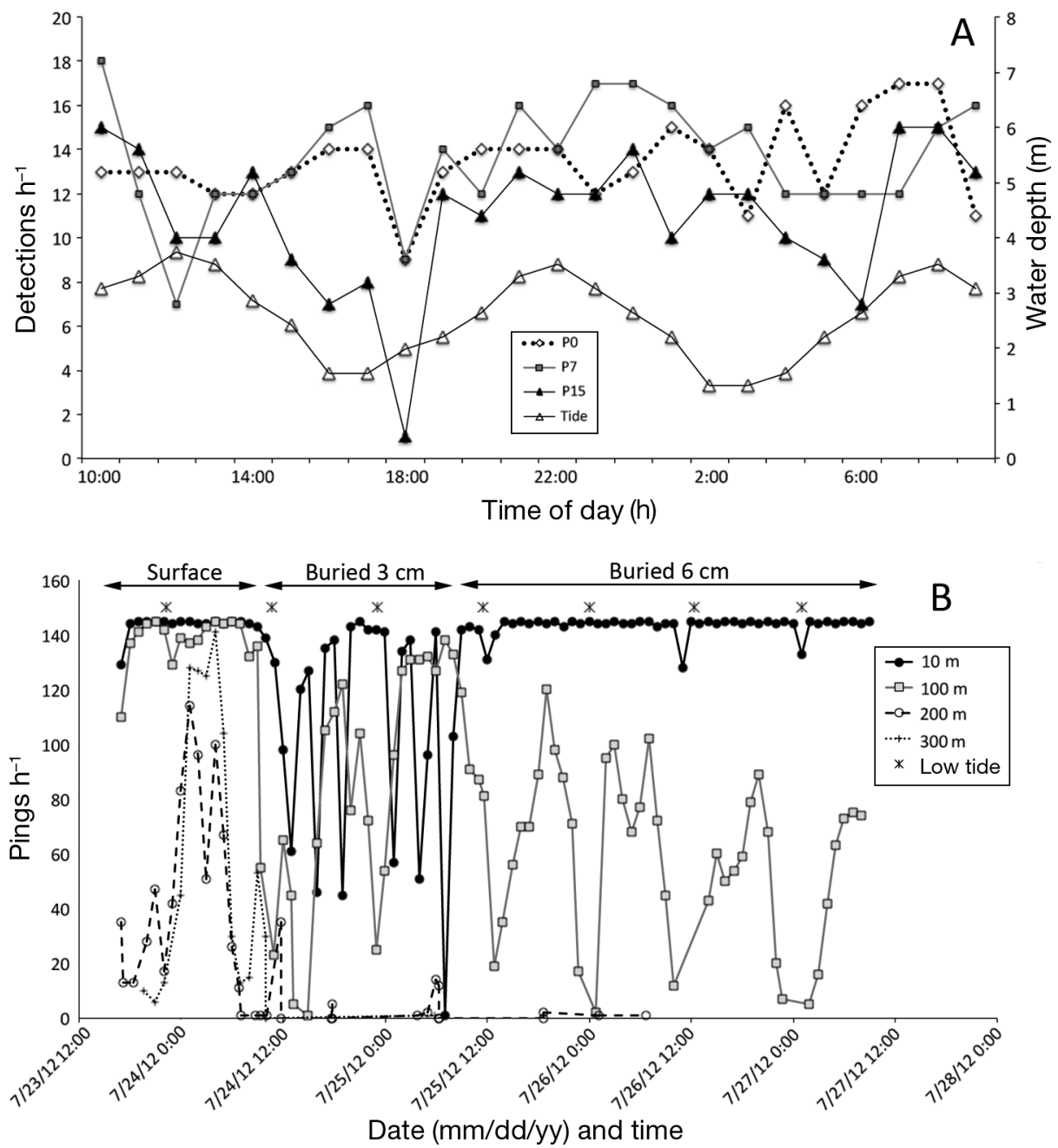

Fig. 2. Influence of V9AP transmitter (pinger) depth on the ability of VR2 receivers to detect signals. (A) Detection rate of a receiver moored $50 \mathrm{~m}$ from pingers that were on the surface (P0), or buried $7 \mathrm{~cm}(\mathrm{P} 7)$ or $14 \mathrm{~cm}$ (P14) in the sediment. Note that changes in water depth did not correlate with detection ability, and that the pinger buried deepest was consistently detected less often the others. (B) A single pinger that transmitted every minute was placed on the bottom for $1 \mathrm{~d}$, then just before 12:00 $\mathrm{h}$ on $7 / 24 / 2012$ it was buried $3 \mathrm{~cm}$ deep in the sand, then further buried $6 \mathrm{~cm}$ the following day. Note how this led to some loss in detections by the VR2Ws, with the greatest attenuation experienced by the receivers furthest away from the pinger. Sporadic signals received by the closest $(10 \mathrm{~m})$ receiver might be due to the divers altering the orientation of the pinger when pushing it into the mud. Symbols at the top of the figure denote peak low tides; during these times when the pinger was $6 \mathrm{~cm}$ into the sediment, the furthest receivers did not detect it, and there was a decrease in detections recorded by the receiver that was $100 \mathrm{~m}$ away
34 to $1.5 \mathrm{~h}^{-1}$ relative to the control situation with the pinger on the surface; Fig. 2B). When the transmitter was buried even further $(6 \mathrm{~cm})$, detections were reduced by $65 \%$ at the $100 \mathrm{~m}$ receiver and by $>90 \%$ at the more distant receivers. In this study, there were several occasions during low tides when fewer transmissions were detected by the receiver that was $100 \mathrm{~m}$ away, and this became more pronounced when the pinger was buried (Fig. 2B). The dominant finding from these 2 experiments was that transmissions were difficult to detect when pingers were buried, and this was most clearly manifested when examining data from the most distant receivers. Therefore for our subsequent analyses, we assumed that when animals were within range of a receiver (i.e. it was detecting transmissions often) and there were gaps in detection, the animals were buried and thus inactive. However, loss of transmissions could also be due to acoustic interference from changing tides, so this should be taken into account when interpreting these data.

\section{Seasonal changes in activity}

During the spring and summer, horseshoe crabs were active $>50 \%$ of the time (Fig. 3B). This period of increased activity was associated with generally higher water temperatures (ca. $20^{\circ} \mathrm{C}$; Fig. 3B). As the water temperature started to drop in the fall and into winter, animals became less active and moved into deeper areas of the estuary (Fig. 3). There was a significant correlation between water temperature and activity $\left(\mathrm{r}^{2}=0.65, \mathrm{p}=0.027\right)$, and water temperature and depth $\left(r^{2}=0.62, p=0.035\right)$, and the relationship between activity and the depth they occupied was very strong (i.e. they were more active when in shallow water; $r^{2}=0.85, p=0.0032$; Fig. 3). 


\section{Seasonal movements}

As documented previously (Watson et al. 2009, Schaller et al. 2010), the horseshoe crabs in this study were located further up into the estuary in the summer, then moved down the estuary as the water temperatures decreased in the fall (Fig. 4). These fall movements down the estuary were also correlated with a shift to the deeper channels (Figs. 3 \& 4).

In November and December 2011, we fitted 6 animals with transmitters specifically to determine when they became active in the spring and initiated movements up into the estuary. All horseshoe crabs overwintered near Fox Point (see Fig. 4), and then in March 2012, during a stretch of unseasonably warm weather, they became quite active and moved rapidly up-estuary towards spawning areas in Great Bay (Figs. $5 \& 6$ ). Water temperature then stabilized for $\sim 2$ wk before another warm period occurred, which caused another surge of activity. While 1 horseshoe crab moved at a rate of $>1 \mathrm{~km} \mathrm{~d}^{-1}$, overall they averaged ca. $0.2 \mathrm{~km} \mathrm{~d}^{-1}$ from 24 to 27 March $(\mathrm{n}=6)$.

\section{Biological rhythms of activity}

We found that horseshoe crabs in the Great Bay Estuary, $\mathrm{NH}$, expressed both daily and tidal rhythms of activity. Of the 13 horseshoe crabs that yielded sufficient data for analyses of biological rhythms (at least $10 \mathrm{~d}$ of continuous data), 6 expressed a statistically significant tidal pattern of activity (Fig. 7), 5 exhibited a daily rhythm, and 2 were arrhythmic. One of the horseshoe crabs that exhibited a daily rhythm was more active at night (Fig. 8 ; a male residing at a mean depth of $4.13 \mathrm{~m}$ in July; tau $=24.0 \mathrm{~h}$ ), and 2 showed a preference for daytime activity during some periods of the year (Fig. 9), but then expressed tidal rhythms during other times (data not shown). As water temperatures dropped in the fall, all animals, regardless of the type of rhythm they expressed, became less active and exhibited less well-defined rhythms (Fig. 10).

There was no clear relationship between the depth occupied by horseshoe crabs and the type of rhythm they expressed. The average depth occupied by animals during the months when they expressed tidal rhythms $(9.4 \pm 1.4 \mathrm{~m})$ was not significantly different from the depths they occupied when they had daily rhythms $(7.8 \pm 1.2 \mathrm{~m})$ (unpaired Student's $t$-test, $\mathrm{p}=$ $0.24)$. This was also evident when examining data from the 2 animals that exhibited both types of rhythms. One of them expressed a daily rhythm during months when it resided at mean depths of 5.4 and
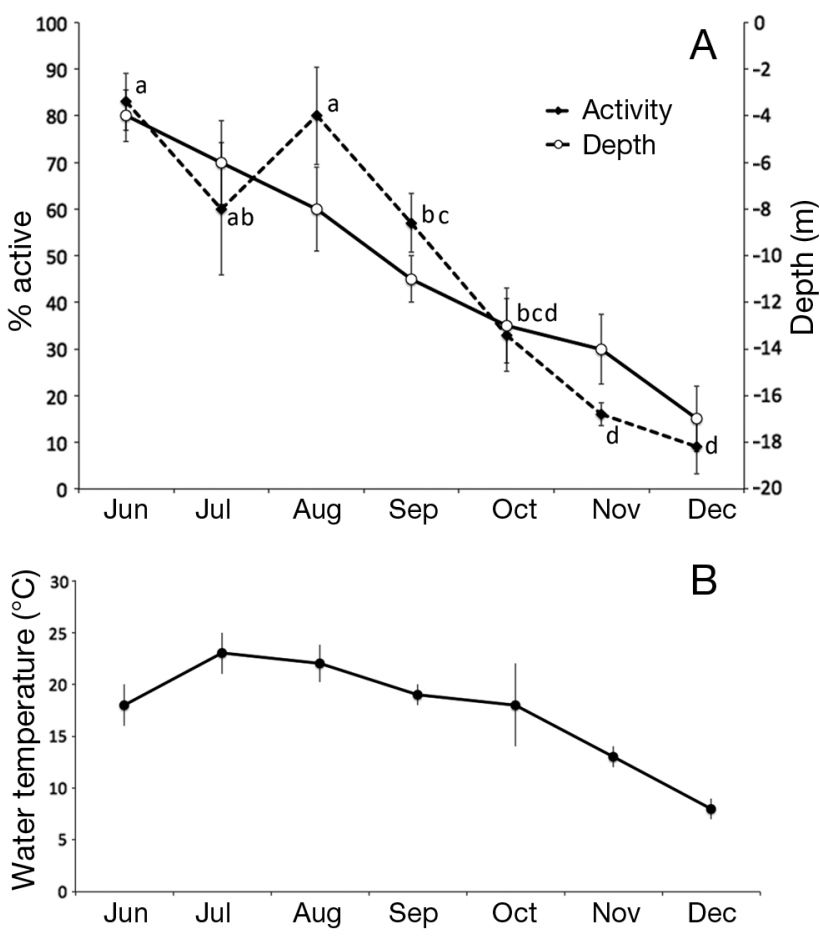

Fig. 3. Mean $( \pm \mathrm{SE})$ monthly (A) horseshoe crab activity and depth and (B) monthly temperatures between June and December. Temperature data were collected from a YSI sonde at the dock of the Jackson Estuarine Laboratory (JEL, Fig. 1). Activity level is based on the percent of time/day that animals were (active). Data were based on values obtained only from animals whose transmitters were detected for at least $1 \mathrm{wk}$ in that month; therefore sample sizes for depth and activity calculations for each month were: June (7), July (7), August (4), September (4), October (4), November (6), December (4). Different lowercase letters indicate monthly activity levels that are significantly different from each other (1-way ANOVA, p < 0.05)

Fig. 4. Locations of 6 horseshoe crabs tagged in June 2010 and at large for at least $40 \mathrm{~d}$. Numbers represent the last 2 numbers of their pinger IDs (see Table 1), and show their most upestuary position during the summer, with arrows pointing to their most down-estuary location in the fall. JEL= Jackson Estuarine Laboratory, where the crabs were tagged and released. Scale bar $=1 \mathrm{~km}$

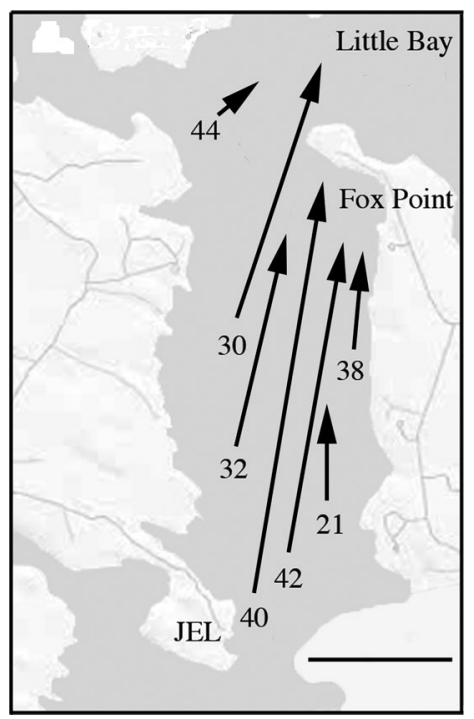




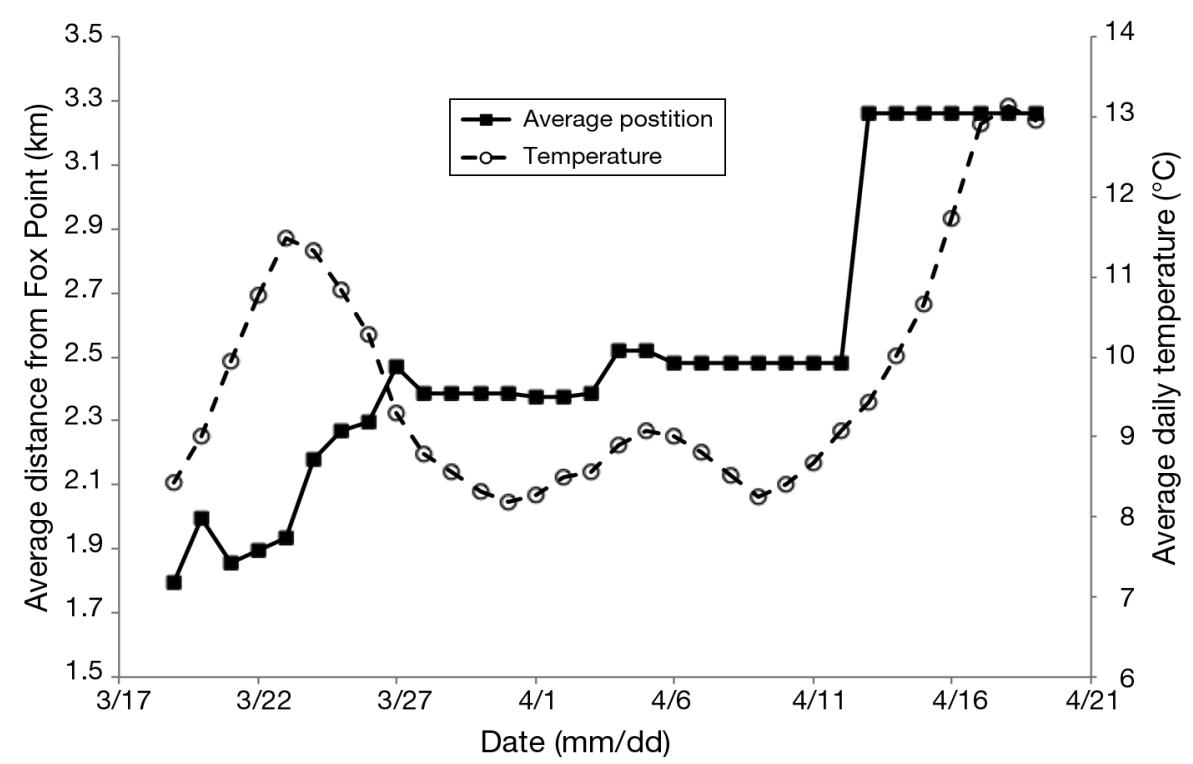

Fig. 5. Movements of 4 horseshoe crabs in the spring as water temperatures increased in March 2012. Black squares: average position of all 4 horseshoe crabs relative to their overwintering area near Fox Point; open circles: average daily temperature at JEL (Fig. 4). Note that the animals initiated their movements up-estuary, towards most spawning beaches, when the water temperature rapidly warmed in midMarch (from $\sim 8$ to $12^{\circ} \mathrm{C}$ ), then again when temperatures increased midApril. In the Great Bay estuary horseshoe crabs typically commence mating in May

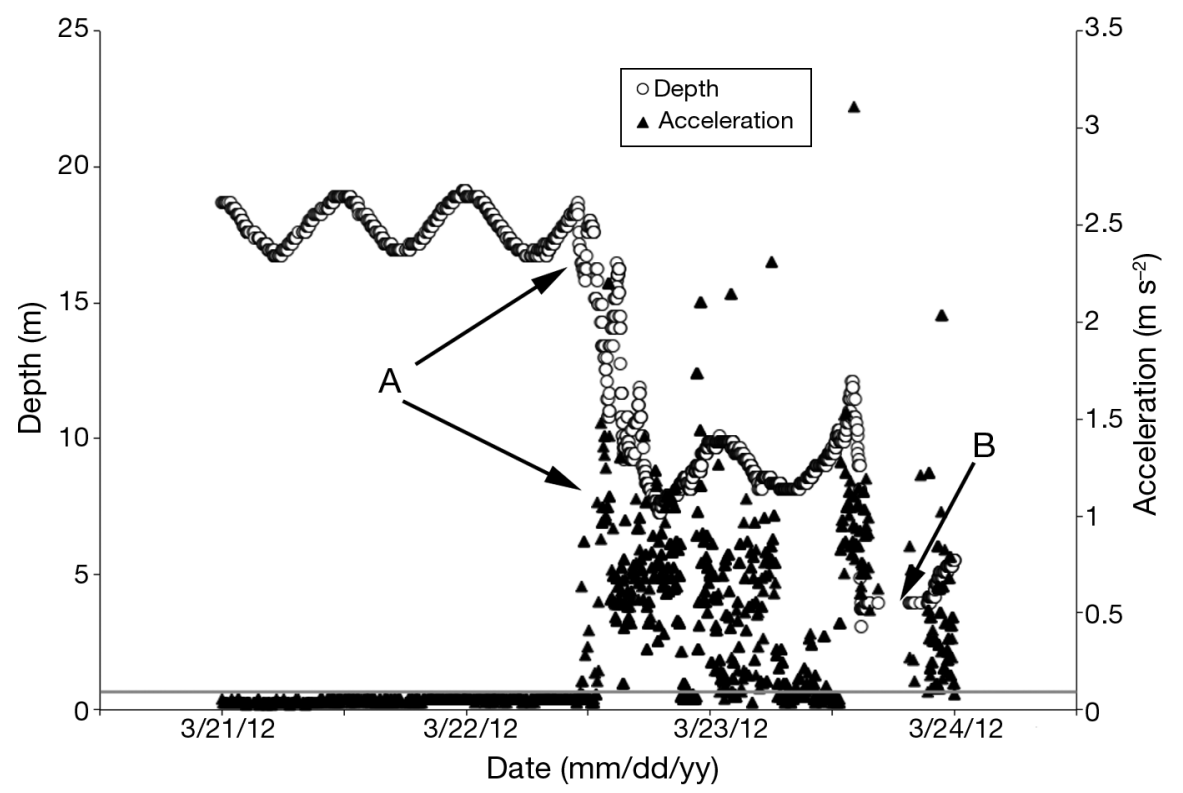

Fig. 6. Simultaneous depth and acceleration data from horseshoe crab \#6508 in spring 2012. The animal was sedentary from $3 / 21 / 12$ to 3/22/12 (gray horizontal line: threshold for considering an animal active), so the depth sensor provides a good representation of the changing tides. Then near peak high tide on $3 / 22 / 12$ (A) it became active and moved into shallow water. Activity declined during low tide on $3 / 23 / 12$, and then increased again near peak high tide as it moved into even shallower water. The gap in the data (B) is most likely the result of this animal being buried in the sediment

$12.7 \mathrm{~m}$, and tidal rhythms when occupying habitats at mean depths of 12.0 and $16.2 \mathrm{~m}$. The other horseshoe crab was always at mean depths ranging from 11.3 to $12.9 \mathrm{~m}$, but switched to a tidal rhythm of activity in October (data not shown).

\section{DISCUSSION}

\section{Rhythms expressed by freely moving horseshoe crabs in their natural habitat}

To our knowledge, this is the first study to continuously record the expression of both tidal and daily rhythms of activity by an aquatic species in its natural habitat. Interestingly, the patterns of horseshoe crab activity we documented, and the variety of rhythms they exhibited, were very similar to those previously demonstrated in the laboratory (Chabot \& Watson 2010, Dubofsky et al. 2013). This was somewhat surprising because in their natural habitat they are exposed to strong tidal cues, and when exposed to artificial tides in the laboratory, most of them readily synchronize their activity to the tides (Watson et al. 2008, 2009, Chabot \& Watson 2010).

Several of the animals in this study expressed a clear preference for daytime or nighttime activity (Figs. 8-10). This is also common in juvenile and adult horseshoe crabs in the laboratory when exposed to artificial L:D cycles (Chabot \& Watson 

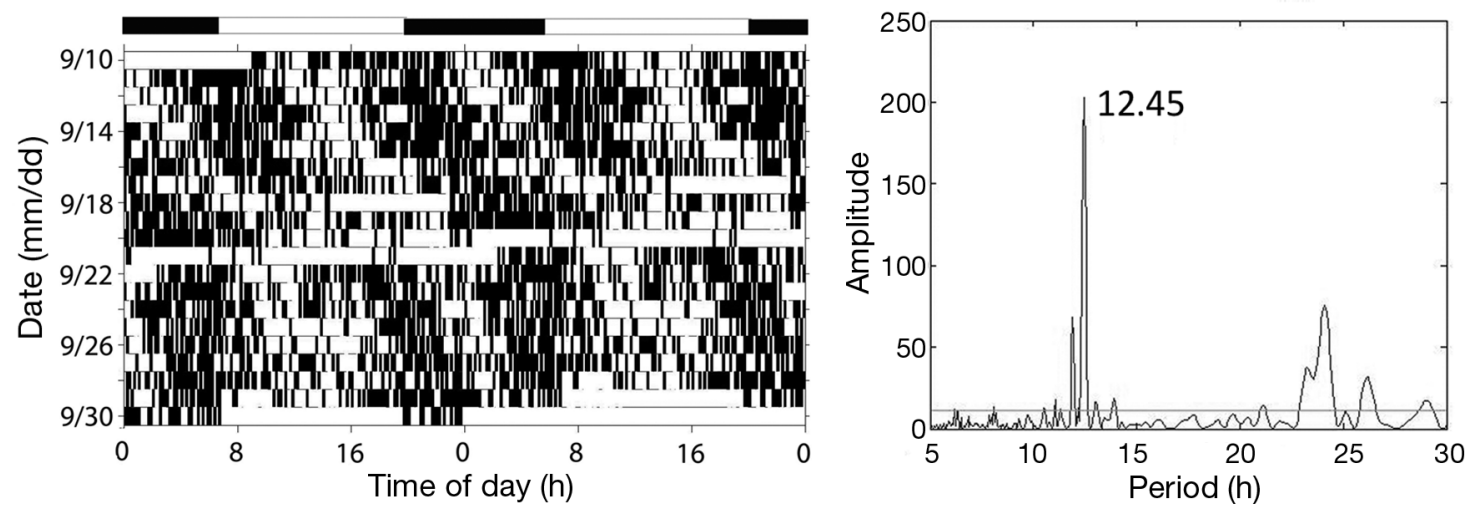

Fig. 7. Actogram of a freely moving horseshoe crab (\#2744, male) in its natural habitat, expressing a tidal rhythm of activity during September. Horizontal bars at the top of the actogram represent daytime (white) and nighttime (black). Activity is double-plotted so that rhythms are more evident; thus each line equals $48 \mathrm{~h}$ of data. Black ticks: bouts of activity; white blanks: inactivity; underlined blanks: gaps in the data that we interpret as animals burrowing in the sediment (thus inactive). This animal tended to be most active during high tides. On 9/10/10, the first day on this actogram, high tide was at 16:30 h. The periodogram (right) shows that the dominant, statistically significant ( $\mathrm{p}<0.05$, line on graph), rhythm had a period of $12.45 \mathrm{~h}$ (amplitude $=$ relative strength of the rhythm). Note that from $\sim 9 / 16$ to 9/22 there may have been less activity during the day high tide than the night high tide

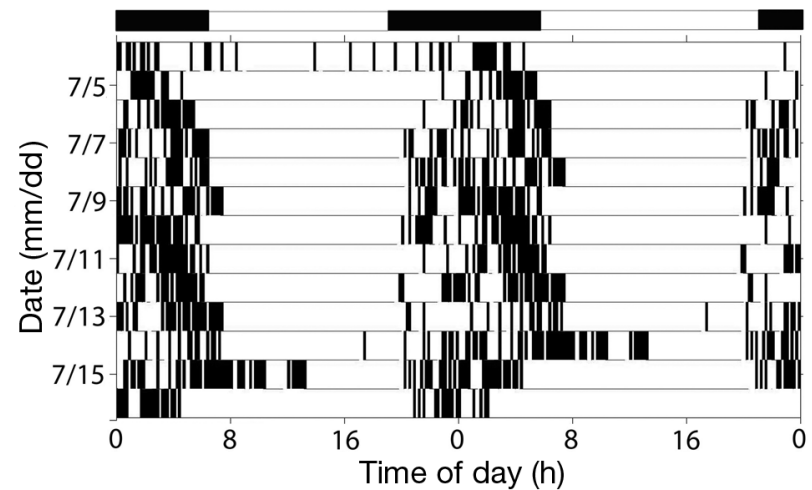

Fig. 8. Actogram of a freely moving horseshoe crab (\#5861, male) exhibiting a nocturnal pattern of activity during the first half of July. Horizontal bars at the top of the actogram represent daytime (white) and nighttime (black). This animal resided at an average depth of $4.13 \mathrm{~m}$ during this month and tau was 24.0 h. See Fig. 7 for a more in-depth description of the graphical features of the actogram

2010, Dubofsky et al. 2013), as well as adult Limulus exposed to ambient light in outdoor tanks, or nearshore enclosures (Watson \& Chabot 2010, Anderson et al. 2013). However, while it is very clear that horseshoe crabs possess a circadian clock that influences visual sensitivity (Barlow 1983), to date the evidence for a circadian clock controlling locomotion is not strong (Dubofsky et al. 2013). An alternative explanation is that some animals have a preference for daytime or nighttime activity (Chabot et al. 2007) for reasons that have yet to be elucidated, and this preference influences-and in some cases over-

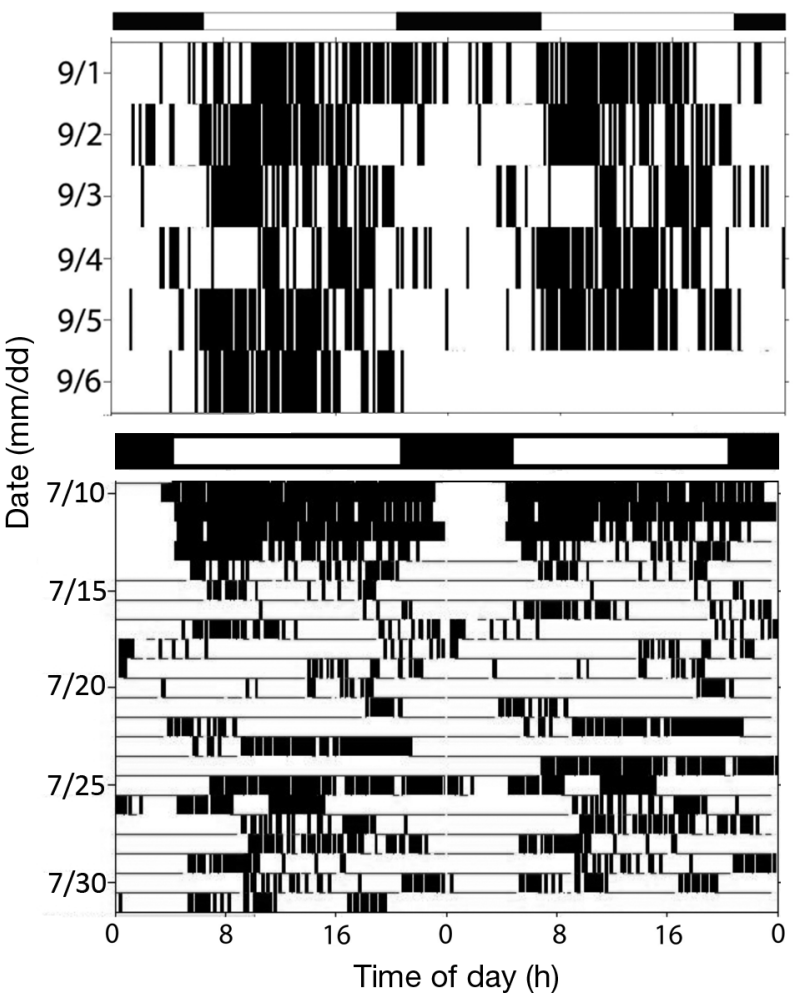

Fig. 9. Actograms of 2 horseshoe crabs (top: \#5865; bottom: \#2740) that expressed a preference for being active during the daytime. Animal \#5865 was a male that resided at a mean depth of $12.8 \mathrm{~m}$ during September; \#2740 was a male who as at $12.7 \mathrm{~m}$ during July. tau $=23.3 \mathrm{~h}$ for \#5865 and $23.6 \mathrm{~h}$ for \#2740. Light/dark bars on the top represent day and night. Note that the days were longer in July. See Fig. 7 for a more in-depth description of how the actogram was constructed 


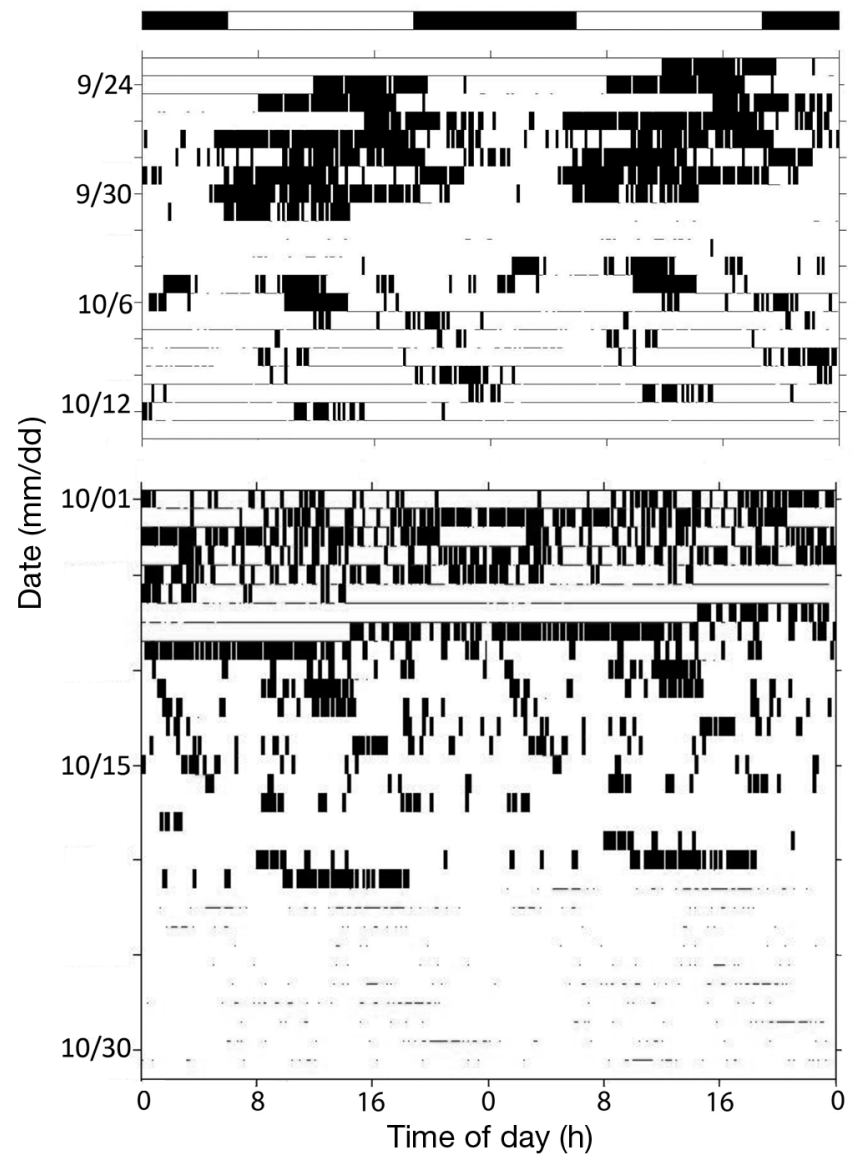

Fig. 10. Actograms of 2 different horseshoe crabs, one from 2010 (top) and one from 2011 (bottom), illustrating the decrease in overall activity that took place as water temperatures dropped in the fall. Horizontal bars at the top of the actogram represent daytime (white) and nighttime (black). The top panel also illustrates a switch from a diurnal ( $t a u=$ $23.3 \mathrm{~h}$ ) to a tidal rhythm ( $\operatorname{tau}=12.5 \mathrm{~h})$. Even though most of the horseshoe crabs moved deeper as the water temperature decreased, this animal remained at basically the same depth in September and October (11.5 to $12.8 \mathrm{~m}$ ), so the change from a daily to a tidal rhythm was not likely due to a change in depth

rides - the control of their locomotion rhythms by an endogenous circatidal clock. In some cases, this influence of light and dark yields a very clear daily rhythm (Fig. 8), while in other cases it manifests itself as a tidal rhythm with only one of the bouts of activity that usually occur at high tide being expressed during either night or day. For example, the activity pattern depicted in Fig. 10 appears to be the manifestation of an animal that preferred to be active during the high tides that occurred during the day (Fig. 10, top). Perhaps in some animals this preference for being active during the light (or dark) portion of the day reaches the point where it completely overrides the influence of the endogenous circatidal clock on activity, and thus they appear to be expressing a clear daily rhythm (Figs. 8 \& 9).

Another possibility is that the preference for nighttime or daytime high tide is related to the relative height of the 2 tides. Field studies have documented increased activity in both nighttime and daytime high tides during mating season, depending on which tide is the highest (Barlow et al. 2001). While a preference for the diurnal high tide has been observed in some horseshoe crab populations (Cohen \& Brockmann 1983), others appear to prefer the night tides (Florida: Rudloe 1979, 1980; Cape Cod, Massachusetts: Barlow et al. 1986). Given the apparent sensitivity of horseshoe crabs to changes in water depth, it is possible that more animals detect the highest of the 2 tides in these locations and thus more animals approach the spawning beaches during the highest tides. However, in the Great Bay estuary both tides are of comparable size, and similar numbers of animals appear on the mating beaches during daytime and nighttime high tides (Watson et al. 2009, H. Cheng unpubl. data). Moreover, even in outdoor tanks where they are not exposed to depth fluctuations, some animals are most active during only 1 of the 2 tides (W. H. Watson unpubl. data). Thus, our working hypothesis at this time is that activity rhythms in horseshoe crabs are influenced by a combination of inputs including an endogenous circatidal clock system, a mechanism for sensing water depth, and L:D cycles. Moreover, it appears that the relative influence of each of these factors varies somewhat from animal to animal.

While horseshoe crabs are often seen spawning during spring and early summer high tides, less is known about their activities during other times of the year. Our recent studies along with the findings of this investigation indicate that they also tend to be most active during the high tides that occur during much of the remainder of the summer and fall (Watson \& Chabot 2010). Based on our high-resolution tracking studies (VEMCO VRAP system; Watson \& Chabot 2010), observations by SCUBA divers, and a study of the pits dug by the crabs while foraging (Lee 2010), horseshoe crabs move into intertidal mudflats to search for food when these areas are submerged during high tides. This conclusion is supported by some of the findings of the current study, showing that (1) during the times of the year when they were most active their mean depth preference was $\sim 4$ to $10 \mathrm{~m}$ as a result of moving back and forth from the edge of the channels to the adjacent mudflats, and (2) when some animals became active during the high tide portion of the tide cycle, they moved into shal- 
lower water (similar to the pattern shown in Fig. 6). Thus, while additional studies are necessary to confirm this hypothesis, the available data suggest that horseshoe crabs periodically forage on mudflats for a large portion of the year, and because some of these mudflats are only accessible during high tides, their activity rhythms are often synchronized to the tides.

\section{Use of accelerometer transmitters to monitor activity}

While there are many ways to monitor animal activity in the laboratory, it is much more challenging in aquatic habitats, especially with animals that move large distances. While traditional tag/recapture and telemetry methods are useful for determining where and when animals move, they are not optimal for investigating finer scale movements such as the biological rhythms these animals express when exposed to the range of cues available in their natural habitat. In previous studies, we used 2 different methods to monitor the daily activity of freely moving horseshoe crabs, and while each yielded useful data, they were not optimal for monitoring biological rhythms. The first method (Watson \& Chabot 2010) involved a high resolution ultrasonic telemetry system (VRAP, VEMCO) that provided precise data about the position of a horseshoe crab fitted with a transmitter; however, if the animal moved out of range of any of the 3 receivers/buoys, data were lost. The second approach (W. H. Watson unpubl.) involved attaching an accelerometer data logger (HOBO pendant, Onset Computer) to an animal so that activity was constantly logged, and moving out of range of receivers was not a problem. A similar approach was used by Whitney et al. (2007) to study the activity patterns of whitetip reef sharks Triaenodon obesus, except the sharks were confined during their study. The drawback of this method is that in order to retrieve the data the animal must be recaptured, which can be difficult in an estuary where visibility for divers is limited. The technique used in the present study shared characteristics of both systems. The accelerometer tag transmitted movement data so activity did not have to be extrapolated from tracks of animal movements, and we were able to detect the signals using individual VR2W receivers rather than an array of 3 receivers, which increased the probability that continuous data could be obtained. As a result, we were able to collect activity data from individual animals long enough to determine the type of rhythm being expressed. In fact, we were able to almost continuously monitor the activity of one horseshoe crab from April to November in 2010. Another advantage of this technique is the ability to activate and inactivate the transmitters so that battery life is not 'wasted' during the time of year when animals are not moving. Thus we were able to fit animals with transmitters in the fall, turn them off for most of the winter and then re-activate them early the following spring, allowing us to determine when they first became active as the water warmed up in March (Figs. 5 \& 6).

The biggest drawback of this approach with this particular species was that we intermittently lost transmissions, apparently due to the fact that the crabs frequently buried in the sediment, which attenuated the transmissions. In order to test this hypothesis, we conducted several studies in which we buried transmitters at varying depths in the sediment and then monitored their transmissions at various distances away using VR2Ws (Fig. 2). It was clear from these tests that if horseshoe crabs buried themselves deep enough to just cover their dorsal carapace, transmitters would be at least $6 \mathrm{~cm}$ under the surface and transmissions would be hard to detect $>100 \mathrm{~m}$ away (Fig. 2). This finding is also supported by our previous investigations using the VRAP system, which detects ultrasonic transmitters and plots positions every 2 to 5 min (Watson \& Chabot 2010). Detections would often stop for short periods and then start up again, with the animal in the exact same location; presumably because the animal would bury itself and then come back out of the sediment. Given a study area that was $\sim 5 \mathrm{~km}$ long it was difficult to maintain VR2Ws close enough to all of the animals at any given time. Thus, we were forced to accept the occasional loss of transmissions, and assumed that when this happened for several hours it was because the animals were buried and not very active. However, periodic gaps in detections could also be the result of currents and thermoclines (Mathies et al. 2014), or animals periodically moving out of range of all our VR2Ws and then back again. While we did detect an apparent influence of tides on our ability to detect pings at a distance of $100 \mathrm{~m}$, when pingers were buried it did not appear that the currents associated with the tides were a common issue for several reasons. First, when tidal patterns were apparent, they should have been more consistent if they were artifacts of the impact of tides on transmissions. However, as illustrated in Fig. 7, the tidal rhythms recorded were somewhat inconsistent from day to day. Second, a number of animals expressed very clear daily rhythms, which should have been 
obscured if the tides were the cause of periodic loss of signals (Figs. $8 \& 9$ ). Finally, during one of the calibration tests, tidal rhythms were not obvious, and the impact of tides was intermittently apparent only when the pinger was buried and the receiver was $>100 \mathrm{~m}$ away. Loss of detections due to burying is a more likely explanation for the following reasons: (1) signals were clearly attenuated when pingers were buried in the sediment (Fig. 2), (2) it seems unlikely that animals would consistently, with a $12.4 \mathrm{~h}$ rhythm, walk out of range of all the receivers and then back into range, day after day, and (3) we did obtain some tidal rhythm data from animals when signals were not attenuated during periods of inactivity (Fig. 9), indicating that not all the tidal rhythms we documented were due to artifacts induced by the tides.

\section{Seasonal changes in activity and depth}

The seasonal changes in depth, location and activity that were expressed by the animals in this study are consistent with the findings of our earlier laboratory and field studies (Watson et al. 2009, Chabot \& Watson 2010). As water temperatures began to drop in the fall, horseshoe crabs in the Great Bay estuary moved down the estuary towards the coast into deeper waters (Figs. $3 \& 4$ ) and became less active (Figs. 3 \& 10). This phenomenon has also been observed in the laboratory, and it appears that the threshold for shifting from one behavioral state to the other is about 8 to $10^{\circ} \mathrm{C}$ (Watson et al. 2009). Although we did not monitor their activity during the winter, our previous studies indicate that they move very little at this time, when water temperatures are typically $<8^{\circ} \mathrm{C}$ (Watson et al. 2009, Schaller et al. 2010). As water temperatures increase in the spring, animals tend to move from their overwintering areas to spawning sites further up in the estuary (Schaller et al. 2010). We were fortunate to document this spring migration very closely in 2012, when there was an unusually warm stretch of weather in March that caused water temperatures to rapidly rise, and this jump to temperatures above $8^{\circ} \mathrm{C}$ appeared to trigger an increase in activity and movements up into Great Bay (Figs. 5 \& 6). The warm spring in 2012 also caused horseshoe crab spawning to commence about 1 mo earlier than usual.

In conclusion, the behavior of horseshoe crabs freely moving in their natural habitat is remarkably similar to their behavior in tanks in the laboratory. They are most active when water temperatures are
$>8$ to $10^{\circ} \mathrm{C}$, they express a variety of biological rhythms, and they have a tendency to be most active during the high tide portion of the tidal cycle. This study illustrates how much can be learned about the normal behavior of animals in their natural habitat using the appropriate technology, as well as how much insight can be gained about the normal behavior of animals from carefully controlled investigations that are only possible in a laboratory setting.

Acknowledgements. We thank the staff at the Jackson Estuarine Laboratory, especially Dave Shay, for making their vessels and facilities available to us, helping all the students involved in the project, and collecting animals. Tom Langley, Jason Goldstein and Beth Dubofsky aided us tremendously with deploying VR2Ws, diving, collecting animals and many other aspects of this study. We are also grateful to Colleen O'Dowd for her help editing the manuscript, and the anonymous reviewers who provided a number of suggestions for improving the manuscript. Funding for this project was provided by the Hamel Center for Undergraduate Research (S.K.J.), NH Sea Grant (W.H.W.) and the National Science Foundation (NSF-IOS 0920342 to C.C.C. and W.H.W.).

\section{LITERATURE CITED}

Anderson RL, Watson WH III, Chabot CC (2013) Sublethal behavioral and physiological effects of the biomedical bleeding process on the American horseshoe crab, Limulus polyphemus. Biol Bull (Woods Hole) 225:137-151

Barlow RB (1983) Circadian rhythms in the Limulus visual system. J Neurosci 3:856-870

Barlow RB, Powers MK, Howard H, Kass L (1986) Migration of Limulus for mating: relation to lunar phase, tide height and sunlight. Biol Bull (Woods Hole) 171:310-329

> Barlow RB, Hitt JM, Dodge FA (2001) Limulus vision in the marine environment. Biol Bull (Woods Hole) 200: 169-176

> Broell F, Noda T, Wright S, Domenici P, Steffensen JF, Auclair JP, Taggart CT (2013) Accelerometer tags: detecting and identifying activities in fish and the effect of sampling frequency. J Exp Biol 216:1255-1264

Chabot CC, Watson WH III (2010) Circatidal rhythms of locomotion in the American horseshoe crab Limulus polyphemus: underlying mechanisms and cues that influence them. Curr Zool 56:499-517

Chabot CC, Kent J, Watson WH III (2004) Daily, circadian and tidal rhythms of locomotor activity in the horseshoe crab Limulus polyphemus. Biol Bull (Woods Hole) 207: 72-75

- Chabot CC, Betournay SH, Braley N, Watson WH III (2007) Circadian and circatidal rhythms of locomotion in the horseshoe crab Limulus polyphemus. J Exp Mar Biol Ecol 345:79-89

Chabot CC, Skinner SJ, Watson WH III (2008) Locomotion rhythms expressed by the horseshoe crab Limulus polyphemus: I. Synchronization by artificial tides. Biol Bull (Woods Hole) 215:34-45

Chabot CC, Yelle JF, O'Donnell CB, Watson WH III (2011) The effects of water pressure, temperature and current cycles on circatidal rhythms expressed by the American 
horseshoe crab Limulus polyphemus. Mar Freshw Behav Physiol 44:43-60

Cohen JA, Brockmann HJ (1983) Breeding activity and mate selection in the horseshoe crab Limulus polyphemus. Bull Mar Sci 33:274-281

Cooke SJ, Midwood JD, Thiem JD, Klimley P and others (2013) Tracking animals in freshwater with electronic tags: past, present and future. Animal Biotel 1:5

DeCoursey PJ (2004) The behavioral ecology and evolution of biological timing systems. In: Dunlap J, Loros JJ, DeCoursey PJ (eds) Chronobiology: biological timekeeping. Sinauer Associates, Sunderland, MA, p 27-66

Dubofsky EA, Simpson SD, Chabot CC, Watson WH III (2013) Patterns of activity expressed by juvenile horseshoe crabs. Biol Bull (Woods Hole) 225:42-49

Ehlinger GS, Tankersley RA, Bush MB (2003) Spatial and temporal patterns of spawning and larval hatching by the horseshoe crab, Limulus polyphemus, in a microtidal coastal lagoon. Estuaries 26:631-640

James-Pirri MJ (2010) Seasonal movement of the American horseshoe crab Limulus polyphemus in a semi-enclosed bay on Cape Cod, Massachusetts (USA) as determined by acoustic telemetry. Curr Zool 56:575-586

James-Pirri MJ, Tuxbury K, Marino S, Koch S (2005) Spawning densities, egg densities, size structure, and movement patterns of spawning horseshoe crabs, Limulus polyphemus, within four coastal embayments on Cape Cod, Massachusetts. Estuaries 28:296-313

Johnson CH, Gwinner E, Karsch FJ, Saunders D, Zucker I, Ball GF (2004) Fundamental properties of circadian rhythms. In: Dunlap J, Loros JJ, DeCoursey PJ (eds) Chronobiology: biological timekeeping. Sinauer Assocociates, Sunderland, MA, p 67-106

Lee WJ (2010) Intensive use of intertidal mudflats by foraging Atlantic horseshoe crabs Limulus polyphemus. Curr Zool 56:611-617

Lyons GN, Halsey LG, Pope EC, Eddington JD, Houghton JDR (2013) Energy expenditure during activity in the American lobster Homarus americanus: correlations with body acceleration. Comp Biochem Physiol A Mol Integr Physiol 166:278-284

Mathies NH, Ogburn MB, McFall G, Fangman S (2014) Environmental interference factors affecting detection range in acoustic telemetry studies using fixed receiver arrays. Mar Ecol Prog Ser 495:27-38

> Moore S, Perrin S (2007) Seasonal movement and resourceuse patterns of resident horseshoe crab Limulus polyphemus populations in a Maine, USA estuary. Estuaries Coasts 30:1016-1026

Nielsen JL, Arrizabalaga H, Fragoso N, Hobday A, Lutcavage M, Sibert J (2009) Tagging and tracking of marine animals with electronic devices. Springer, New York, NY

Palmer JD (1995) The biological rhythms and clocks of intertidal animals. Oxford University Press, New York, NY

Payne NL, Gillanders BM, Seymour RS, Webber DM, Snelling EP, Semmens JM (2011) Accelerometry estimates field metabolic rate in giant Australian cuttlefish Sepia apama during breeding. J Anim Ecol 80:422-430 Rudkin DM, Young GA (2009) Horseshoe crabs: an ancient

Editorial responsibility: Richard Osman,

Edgewater, Maryland, USA ancestry revealed. In: Tanacredi JT, Botton ML, Smith DR (eds) Biology and conservation of horseshoe crabs. Springer, New York, NY, p 25-44

Rudloe A (1979) Locomotor and light responses of larvae of the horseshoe crab Limulus polyphemus (L.). Biol Bull (Woods Hole) 157:494-505

Rudloe A (1980) The breeding behavior and patterns of movement of horseshoe crabs Limulus polyphemus in the vicinity of breeding beaches in Apalachee Bay, Florida. Estuaries 3:177-183

Rudloe A (1985) Variation in the expression of lunar and tidal behavior rhythms in the horseshoe crab, Limulus polyphemus. Bull Mar Sci 36:388-395

Schaller SY, Watson WH III, Chabot CC (2010) Seasonal movements of horseshoe crabs Limulus polyphemus in the Great Bay Estuary, New Hampshire (USA). Curr Zool 56:587-598

Short FT (1992) The ecology of the Great Bay Estuary, New Hampshire and Maine: an estuarine profile and bibliography. NOAA Coastal Ocean Program Publication, Durham, NH

Shuster CN (2001) Two perspectives: horseshoe crabs during 420 million years worldwide, and the past 150 years in Delaware Bay. In: Tanacredi JT (ed) Limulus in the limelight. Kluwer Academic Press, New York, NY, p 17-40

Smith DR, Brousseau LJ, Mandt MT, Millard MJ (2010) Age and sex specific timing, frequency, and spatial distribution of horseshoe crab spawning in Delaware Bay: insights from a large-scale radio telemetry array. Curr Zool 56:563-574

Watson WH III, Chabot CC (2010) High resolution tracking of adult horseshoe crabs Limulus polyphemus in a New Hampshire estuary using a fixed array ultrasonic telemetry. Curr Zool 56:599-610

- Watson WH III, Bedford L, Chabot CC (2008) Dissociation between circadian rhythms of visual sensitivity and circatidal rhythms of locomotion in the American horseshoe crab Limulus polyphemus. Biol Bull (Woods Hole) 215: $46-56$

Watson WH III, Schaller SY, Chabot CC (2009) The relationship between small- and large-scale movements of horseshoe crabs in the Great Bay estuary and Limulus behavior in the laboratory. In: Tanacredi JT, Botton ML, Smith DR (eds) Biology and conservation of horseshoe crabs. Springer, New York, NY, p 131-148

Whitney NM, Papastamatiou YP, Holand KN, Lowe CG (2007) Use of an acceleration data logger to measure diel activity patterns in captive whitetip reef sharks, Triaenodon obesus. Aquat Living Resour 20:299-305

Williams TM, Fuiman LA, Horning M, Davis RW (2004) The cost of foraging by a marine predator, the Weddell seal Leptonychotes weddellii: pricing by the stroke. J Exp Biol 207:973-982

Wilson RP, White CR, Quintana F, Halsey LG, Liebsch N, Martin GR, Butler PJ (2006) Moving towards acceleration for estimates of activity-specific metabolic rate in freeliving animals: the case of the cormorant. J Anim Ecol 75: 1081-1090

Submitted: April 30, 2015; Accepted: November 16, 2015 Proofs received from author(s): December 10, 2015 